\title{
Development of Ketoprofen-p-Aminobenzoic Acid Co-Crystal: Formulation, Characterization, Optimization and Evaluation
}

\section{Meenakshi Bhatia}

Guru Jambheshwar University of Science and Technology

\section{Ashwani Kumar}

Guru Jambheshwar University of Science and Technology

\section{Vikas Kumar}

Guru Jambheshwar University of Science and Technology

Sunita Devi ( $\sim$ sunitamechu1504@gmail.com)

Guru Jambheshwar University of Science and Technology

\section{Research Article}

Keywords: Ketoprofen, p-aminobenzoic acid, Co-crystal, Solubility enhancement, Solvent evaporation.

Posted Date: June 16th, 2021

DOI: https://doi.org/10.21203/rs.3.rs-596789/v1

License: (9) This work is licensed under a Creative Commons Attribution 4.0 International License. Read Full License 


\section{Development of Ketoprofen-p-aminobenzoic acid Co-crystal: Formulation,}

2 characterization, optimization and evaluation

3 Meenakshi Bhatia ${ }^{1}$, Ashwani $\operatorname{Kumar}^{1}$, Vikas Kumar $^{2}$ and Sunita Devi ${ }^{1 *}$

$4{ }^{1}$ Departmental of Pharmaceutical Sciences, Guru Jambheshwar University of Science and Technology, 5 Hisar, 125001, India

$6{ }^{2}$ Departmental of Chemistry, Guru Jambheshwar University of Science and Technology, Hisar, 125001, 7 India

8

9

10

11

12

13

14

15

16

17

18

19

$20 *$ Corresponding author:

21 Sunita Devi,

22 Drug Delivery Research laboratory, Department of Pharmaceutical Sciences,

23 Guru Jambheshwar University of Science and Technology, Hisar, 125001, India

24 e-mail: sunitamechu1504@gmail.com 

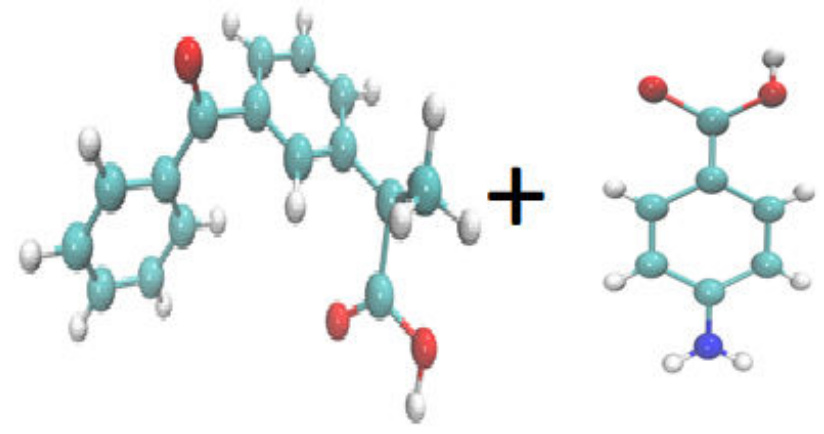

ketoprofen p-aminobenzoic acid

27

28

29

30

31

32

33

34

35

36

37

38

39

40

41

42 
ABSTRACT

Co-crystal is a promising class of solids that may provide options for improved properties. In the

present study, ketoprofen- $p$-aminobenzoic acid (KP-PABA) co-crystal were prepared to sought enhanced solubility and dissolution rate of drug. KP-PABA co-crystal were prepared by solvent evaporation technique employing central composite experimental design, selecting independent variables as concentration of drug and PABA whereas dependent variables were assumed to be solubility and \% drug release. The optimized batch as suggested by the experimental design was characterized by FTIR, DSC, XRD, SEM and NMR studies and further, evaluated for in-vitro and in-vivo anti-inflammatory and analgesic activities. The solubility and \% drug release of different batches of co-crystal was found to be between $34.20-60.11 \mu \mathrm{g} / \mathrm{ml}$ and $68.11-93.45 \%$, respectively. Co-crystal containing ketoprofen and PABA in molar ratio (1:1) was found to be optimized formulation batch. Physical characterization by X-ray diffraction spectra and differential scanning calorimetric studies confirms the crystallinity of prepared co-crystal. The half maximal inhibitory concentration $\left(\mathrm{IC}_{50}\right)$ values for in-vitro anti-inflammatory activity comes out to be $34.04 \mu \mathrm{M}$ for ketoprofen and $4.373 \mu \mathrm{M}$ for optimized formulation, exhibiting almost 8fold amplification indicating higher anti-inflammatory effect of optimized batch as compared to drug ketoprofen. The results of in-vivo anti-inflammatory activity carried out by rat paw edema method revealed that the optimized batch of co-crystal preparation provided a significant $\%$ inhibition in paw volume in contrast to standard drug in wistar rats. In this case, a crystalline molecular complex of drug Ketoprofen, that demonstrate poor aqueous solubility, with paminobenzoic acid was recognized that further set out an improvement in solubility and also in anti-inflammatory activity of the drug in wistar rats. evaporation. 


\section{INTRODUCTION}

74 Co-crystal are described as a multicomponent crystalline material possessing two or more

75 molecules (i.e., drug and coformer) that are connected by noncovalent interactions in the same 76 crystal lattice [1,2]. Co-crystal have the ability to improve the drug dissolution, bioavailability, 77 hygroscopicity, solubility, processability and physical/chemical stability of the compound as compared to active pharmaceutical ingredient (API) $[3,4]$. Co-crystallization is an advanced method to improve pharmaceutical solid dosage form. The preference of a method to produce cocrystal is crucial and depends on different factors for example thermal stability, alteration in solubility of coformers and API in particular solvents, tendency to form stable polymorphs or solvates and availability of a sufficient amount of the substance [5]. The selection of suitable coformer for co-crystallization is based on aqueous solubility of coformer, hydrogen bonding, non-covalent bonding, carbon chain length and molecular recognition. The difference between pKa value of API and coformer (i.e., $\Delta \mathrm{pKa}$ ) also depicts the co-crystal formation capability of a coformer with a given API [6, 7]. According to Berry and Steed, salt formation occurs when $\Delta \mathrm{pKa}$ value remains in close proximity to that of a base however co-crystal will be formed if this value exists close to acid [8]. The formation of co-crystal is formed if multiple H-bonds are formed $[9,10]$. Co-crystal of various drugs with different coformers are listed as ketoconazole with $p$-amino benzoic acid and nicotinamide, telmisartan with chitosan, aceclofenac with chitosan, tadalafil with methylparaben, carbamazepine with nicotinamide, piroxicam with PEG 4000, PVP K30, acetazolamide with theophylline and piperazine and 5-Fluorouracil with gentisic acid, 3,4-dihydroxybenzoic acid and 4-aminopyridine etc. that have been synthesized employing different techniques viz. solvent evaporation [11], solvent change approach [12, 13], solvent drop grinding [14], solution cooling crystallization, solvent evaporation, melting and cryomilling [15], slow crystallisation [16], liquid-assisted grinding and solvent evaporation [17], solvent-assisted grinding and solution crystallization [18].

Ketoprofen $\left(\mathrm{C}_{16} \mathrm{H}_{14} \mathrm{O}_{3}\right)$ belongs to $\mathrm{BCS}$-II, is a propionic acid derivative and can be taken orally to treat inflammatory diseases for instance rheumatoid arthritis, osteoarthritis, musculoskeletal disorders or postoperative pain etc. [19]. The anti-inflammatory property of ketoprofen is due to inhibition of enzyme cyclooxygenase-I and II, thus curtailing the formation of precursors of 
prostaglandins and thromboxanes. Several methods of improving the solubility or dissolution rate of ketoprofen have been put forward like soild dispersion [20, 21], liquisolid [22], microemulsion-based gel [23], emulgels [24], nanoparticles [25-27], solid lipid nanoparticles (SLNs) [28], prodrug with pectin [29], micro and nanocomposite with PLGA [30] etc. Although the co-crystal of ketoprofen with conformer nicotinamide [31] are known. $P$ aminobenzoic acid (PABA) as a coformer purposed in this study is a member of the vitamin B complex and is generally recognized as safe (GRAS) [32]. The ketoprofen and PABA were selected on the basis of the $\mathrm{pKa}$ rule. Benzoic acid has $\mathrm{pKa}$ value of 4.21 whereas $\mathrm{pK}_{\mathrm{a}}$ value for ketoprofen is 3.88 and the value of $\Delta \mathrm{pKa}\left(\mathrm{pKa}_{\mathrm{acid}}-\mathrm{pKa} \mathrm{a}_{\text {base }}\right)$ is -1.36 and correlate to Bhogala et al., at negative values of $\Delta \mathrm{pKa}$, co-crystal development is predictable [33].

In the present piece of research-work, easy and consistent technique of solvent evaporation was employed for composing the ketoprofen-PABA co-crystal seeking improved dissolution of drug. The preparation of co-crystal was accomplished as per central composite experimental design (CCD) by experimental design protocol selecting 2-factors at 3 levels (Design Expert software version 11.0). DSC, FT-IR, XRD, SEM and NMR studies were utilized to characterize the optimized formulation. The optimized formulation was further evaluated for both in-vitro and invivo activities.

\section{MATERIALS AND METHODS}

\section{Materials}

Ketoprofen (KP) was obtained from Infinity Laboratories Pvt. Ltd (Behra, India). p-amino benzoic acid (PABA) was supplied by Central Drug House (P) Ltd., New Delhi. Sodium chloride, acetic acid, carrageenan, ethanol, di-sodium hydrogen orthophosphate, potassium dihydrogen orthophosphate was procured from Hi-Media lab. Pvt. Ltd. All other chemicals \& reagents used in the study were of analytical grade and used as received.

\section{Methods}

\section{Synthesis of Ketoprofen - p-amino benzoic acid (KP-PABA) co-crystal}

Ketoprofen - $p$-amino benzoic acid (KP-PABA) co-crystal was prepared by the solvent evaporation method as reported earlier [34]. Ketoprofen and PABA were used in stoichiometrically equal ratio and after carefully weighing were dissolved in $10 \mathrm{~mL}$ of acetic acid 
131 in a sealed flask and is kept under continuous stirring on a magnetic stirrer for $2 \mathrm{~h}$ while 132 maintaining the temperature at $60{ }^{\circ} \mathrm{C}$. The clear solution so formed was then filtered through $1335 \mu \mathrm{m}$ filter paper and allowed to evaporate slowly at room temperature under a fume hood.

\section{Experimental Design}

135 The preparation of co-crystal using ketoprofen and PABA was optimized using 2-factor, 3 level 136 CCD. The concentration of ketoprofen $(254.29-508.58 \mathrm{mg})\left(\mathrm{X}_{1}\right)$ and concentration of PABA 137 (137.14-274.28 mg) $\left(\mathrm{X}_{2}\right)$ were designated as formulation variables whereas the \% drug release 138 and solubility $(\mu \mathrm{g} / \mathrm{ml})$ were picked as response variables (Table I). Each independent variable 139 was considered at three levels (i.e. -1, 0, and 1).

\section{Solubility studies}

141 Ketoprofen pure drug and each batch of KP-PABA co-crystal formulations containing 142 ketoprofen equivalent to $10 \mathrm{mg}$ was dispersed in $10 \mathrm{ml}$ of distilled water, separately and are kept 143 on continuous shaking for $48 \mathrm{~h}$ for equilibration at room temperature $\left(25^{\circ} \mathrm{C}\right)$ to determine the 144 solubility of ketoprofen. The obtained solution was filtered by $0.45 \mu \mathrm{m}$ millipore filter paper and 145 the drug content was determined by taking absorbance at $260 \mathrm{~nm}$ using $u v$-vis 146 spectrophotometer. The amount of drug was calculated using the calibration curve in water.

\section{Determination of drug content}

148 The different batches of KP-PABA co-crystal formulations containing drug equivalent to $5 \mathrm{mg}$

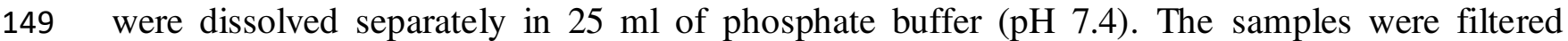
150 through $0.45 \mu \mathrm{m}$ milipore filters and after appropriate dilution the samples were analyzed by $u v$ 151 vis spectrophotometer at 260nm [35].

152 Total Drug Content (TDC) was calculated by the following equation.

153 Total drug content $(\%)=\frac{\text { Weight of drug in cocrystal }}{\text { Weight of cocrystal }} \times 100$

\section{In vitro drug release profile}

155 In vitro dissolution studies were performed using USP type II dissolution apparatus. Dissolution 156 studies of pure drug (Ketoprofen) and each batch of KP-PABA co-crystal formulation containing 157 drug equivalent to $20 \mathrm{mg}$ were conducted in $900 \mathrm{ml}$ phosphate buffer $(\mathrm{pH} 7.4)$ at $37 \pm 0.5^{\circ} \mathrm{C}$ with a 
158 continuous stirring speed of $50 \mathrm{rpm}$. The powder was dispersed over the dissolution medium. 159 Aliquots of sample $(5 \mathrm{ml})$ was withdrawn at different time intervals for 60 minutes and replaced with an equivalent amount of the dissolution medium to retain sink conditions during the experiment. Samples were filtered through $0.45 \mu \mathrm{m}$ milipore filters and the concentration of

162 ketoprofen in the samples was determined by measuring the absorbance of the samples at a 163 wavelength of $260 \mathrm{~nm}$ using the $u v$-vis spectrophotometer followed by determination of 164 mechanism of release by fitting the release rate data in various release kinetic models.

\section{Characterization}

\section{Fourier Transform Infrared Spectroscopy (FT-IR)}

167 Ketoprofen, PABA and optimized batch of KP-PABA co-crystal formulation were exposed to 168 FT-IR spectroscopy. FTIR spectroscopy was directed by a Perkin-Elmer, Spectrum, US 169 spectrophotometer and the spectrum was documented in the wavelength region of $4000 \mathrm{~cm}^{-1}$ to 170 $400 \mathrm{~cm}^{-1}$ using $\mathrm{KBr}$ pellet method. The method involves dispersing of sample in $\mathrm{KBr}$ and 171 compressing into disc by applying a pressure of $50 \mathrm{~kg} / \mathrm{cm}^{2}$ in hydraulic press.

\section{Powder X-ray diffraction (PXRD)}

173 The ketoprofen, PABA, and optimized batch of KP-PABA co-crystal formulation powder 174 samples were examined using an X-ray diffractometer (Miniflex 2, Rigaku, Japan) from $0 \circ$ to 80॰ 175 diffraction angle (2Ө). The Miller index $\left(\mathrm{d}_{\mathrm{hkl}}\right)$ signifies direction and plane in the crystal and is 176 determined using Bragg's equation (equation 2).

$$
\mathrm{n} \lambda=2 \mathrm{~d}_{\mathrm{hkl}} \operatorname{Sin} \theta
$$

178 Here $\lambda$ and $n$ denote the wavelength $(1.5418 \AA)$ and order ( $n=1$, first order), respectively; $\theta$ is the 179 Bragg's angle.

\section{Differential scanning Calorimetry (DSC)}

181 Thermal behavior of ketoprofen, PABA and optimized batch of KP-PABA co-crystal 182 formulation was studied using a DSC (Mettler Toledo, Switzerland), heated the samples at 
temperatures within the range of $20-250^{\circ} \mathrm{C}$ with a scanning rate of $10^{\circ} \mathrm{C} / \mathrm{min}$ in aluminum pans under nitrogen flow at a rate of $50 \mathrm{ml} / \mathrm{min}$.

\section{Scanning electron microscopy (SEM)}

The surface morphology and shape of optimized batch of KP-PABA co-crystal formulation was examined using SEM (JSM-6100 scanning microscopy, Japan). The sample (optimized batch) after coated with gold was mounted on aluminium stub containing double adhesive carbon tape. The photographs were observed at acceleration voltage of $10 \mathrm{kV}$.

\section{Nuclear Magnetic Resonance (NMR) Spectroscopy}

The NMR spectra of ketoprofen, PABA and optimized batch of KP-PABA co-crystal formulation after dissolving in DMSO- $\mathrm{d}_{6}$ were examined using Bruker Avance AV 400 NMR spectrometer (Bruker, Karlsruhe, Germany) to get solution ${ }^{13} \mathrm{C}$ NMR data at a temperature of $293 \mathrm{~K}$ using Tetramethylsilane (TMS) as an internal standard [36]. Data was interpreted using Mnova program (Mestrelab Research, Santiago de Compostela, Spain).

\section{Stability studies}

The optimized batch of co-crystal was kept for the accelerated stability studies according to ICH guidelines $\left(40 \pm 2{ }^{\circ} \mathrm{C}\right.$ and $\left.75 \pm 5 \% \mathrm{RH}\right)$ for a period of 6 months in a stability chamber. The samples were placed in hermetically sealed vials containing rubber plugs and aluminum bung. The stored co-crystal were taken out after 6 months and evaluated for the drug content (according to the method described in earlier section of drug content, $n=3$ ) and for any physical changes [13].

\section{Biological evaluation of KP-PABA co-crystal}

\section{In-vitro anti-inflammatory activity}

Egg albumin denaturation method was employed to evaluate in-vitro anti-inflammatory activity of drug ketoprofen and optimized batch of KP-PABA co-crystal [37]. The mixture contained of pure fresh hen's egg albumin $(0.2 \mathrm{ml})$, Phosphate buffer saline, $\mathrm{pH} 7.4(2.8 \mathrm{ml}))$ and $2 \mathrm{ml}$ of different concentrations of KP-PABA co-crystal formulation (containing ketoprofen equivalent to $10 \mathrm{mg})(125,250,500,750 \& 1000 \mu \mathrm{g} / \mathrm{ml}$ in Dimethyl sulfoxide as solvent). After incubation (Caltan, NSW, India) for $15 \mathrm{~min}$ at a temp of $37 \pm 2{ }^{\circ} \mathrm{C}$, the temperature of mixture was raised to 
$21170^{\circ} \mathrm{C}$. After cooling at room temperature, the absorbance measured at $\lambda_{\max }$ of $260 \mathrm{~nm}$. Similar 212 procedure is followed for the model drug ketoprofen containing same concentrations as for the 213 formulation, as a reference or control [38].

214 The $\%$ inhibition of protein denaturation was calculated as per equation 3

$$
\% \text { Inhibition }=\frac{\text { Abs.of control }- \text { Abs. of sample }}{\text { Abs.of control }} \times 100
$$

216 The half maximal inhibitory concentration $\left(\mathrm{IC}_{50}\right)$ values of ketoprofen and optimized formulation 217 was measured by nonlinear regression analysis using Graph Pad Prism 5.0 for Windows.

In-vivo carrageenan-induced anti-inflammatory activity

219

220

221

222

223

The protocol with registration no. CPCSEA Reg. no-IAEC/2020/10-18 was approved for animal study by the Animal Ethical Committee, Guru Jambheshwar University of Science and Technology, Hisar, India. Wistar rats (180-210 g) of either sex were divided into three groups comprising of six animals each. Group I (Control treated) with carrageenan was kept as control, Group II (standard Drug) was treated with drug-ketoprofen $(10 \mathrm{mg} / \mathrm{kg}$ ) and Group III (Test compound) was treated with KP-PABA co-crystal (equivalent to ketoprofen $10 \mathrm{mg} / \mathrm{kg}$ ) body weight administrated orally. $0.1 \mathrm{ml}$ of $1 \%$ suspension of carrageenan in normal saline, was administered as subplantar injection in the left hind paw of albino wistar rats, after $1 \mathrm{~h}$ after of oral administration of the test materials. The paw volume was measured using vernier caliper at $1,2,3,4,5$ and $6 \mathrm{~h}$ after the carrageenan injection $[39,40]$. The $\%$ inhibition in paw volume was calculated by using equation 4 ,

$$
\% \text { inibition }=\frac{V c-V t}{V c} \times 100
$$

Where $V_{c}$ and $V_{t}$ is the inflammatory increase in paw volume control group and the inflammatory increase in paw volume in test group respectively [41].

\section{Analgesic activity (Tail flick method)}

Analgesic activity was measured by tail flick method using a radiant type analgesiometer. In tail flick method pain was produced by placing the tip of the tail on the heat source. Mice (25-30g) of either sex were divided into three groups (test, standard and control) containing six animals in each group. The tail flick reaction time for each animal was recorded six times before administering the drug and the mean was used as predrug reaction time. A dose of the standard drug (Ketoprofen) and test compound (optimized batch of KP-PABA co-crystal) containing 
ketoprofen equivalent to $5 \mathrm{mg} / \mathrm{kg}$ of body weight in $0.9 \% \mathrm{w} / \mathrm{v}$ sterile saline was administered to animals. The test and standard group received drug orally while the control group was catered with vehicle only. After administration of the drug, the tail flick reaction time was measured at different time interval as $0,1,2,3,4$ and $5 \mathrm{~h}$ [42].

$244 \%$ Analgesic activity (PAA) was calculated by using the equation 5$$
P A A=(T 2-T 1) / T 1 * 100
$$

Where, $T_{1}$ and $T_{2}$ are reaction time in seconds before and after treatment with drug, respectively. Data was analyzed by one-way ANOVA method and further followed by Tukey's post-hoc test, statistically and is denoted as $\mathrm{P}$ value.

\section{RESULTS}

250 The preparation of co-crystal using ketoprofen and PABA was optimized using 2-factor, 3 level CCD. The concentration of ketoprofen $\left(\mathrm{X}_{1}\right)$ and concentration of PABA $\left(\mathrm{X}_{2}\right)$ were designated as 252 formulation variables whereas the \% drug release and solubility $(\mu \mathrm{g} / \mathrm{ml})$ were specified as 253 response variables Formulation parameters and responses for experimental design for different 254 batches of KP-PABA co-crystal as exhibited in Table 1. The TDC of different batches of KP255 PABA co-crystal was observed between 97.01 to $98.92 \%$. No physical changes were observed 256 during stability studies and even after six months.

\section{Solubility studies}

258 The outcome of solubility $\left(\mathrm{Y}_{1}\right)$ and in-vitro drug release profile $\left(\mathrm{Y}_{2}\right)$ of the KP-PABA co-crystal, 259 formulated according to the experimental design expert protocol is exhibited in Table I. The 260 responses generated were fitted into numerous polynomial models.

261 Table I. Formulation parameters and responses for experimental design.

\begin{tabular}{|c|c|c|c|c|c|}
\hline Batch & $\begin{array}{l}\text { Conc. Of } \\
\text { Ketoprofen } \\
(\mathrm{mg})\left(\mathrm{X}_{1}\right)\end{array}$ & $\begin{array}{l}\text { Conc. Of } \\
\text { PABA (mg) } \\
\left(\mathrm{X}_{2}\right)\end{array}$ & $\begin{array}{l}\text { Solubility } \\
(\mu \mathrm{g} / \mathrm{ml})\left(\mathrm{Y}_{1}\right)\end{array}$ & $\begin{array}{l}\% \quad \text { In-vitro } \\
\text { drug release } \\
\text { in } 60 \text { min. } \\
\left(\mathrm{Y}_{2}\right)\end{array}$ & $\begin{array}{l}\text { Total drug } \\
\text { content }(\%)\end{array}$ \\
\hline 1 & 508.58 & 137.14 & $45.02 \pm 0.18$ & $79.47 \pm 0.33$ & $97.78 \pm 0.13$ \\
\hline 2 & 381.43 & 205.71 & $53.42 \pm 0.3$ & $85.12 \pm 0.36$ & $98.42 \pm 0.04$ \\
\hline
\end{tabular}




\begin{tabular}{|l|l|l|l|l|l|}
\hline 3 & 381.43 & 274.28 & $58.14 \pm 0.2$ & $85.69 \pm 0.22$ & $97.12 \pm 0.08$ \\
\hline 4 & 381.43 & 205.71 & $53.12 \pm 0.21$ & $82.94 \pm 0.41$ & $97.94 \pm 0.06$ \\
\hline 5 & 381.43 & 205.71 & $55.19 \pm 0.19$ & $79.80 \pm 0.34$ & $97.91 \pm 0.08$ \\
\hline 6 & 381.43 & 137.14 & $42.32 \pm 0.22$ & $69.74 \pm 0.8$ & $97.70 \pm 0.03$ \\
\hline 7 & 508.58 & 274.28 & $60.11 \pm 0.26$ & $93.45 \pm 0.15$ & $98.92 \pm 0.02$ \\
\hline 8 & 381.43 & 205.71 & $52.23 \pm 0.27$ & $83.87 \pm 0.09$ & $98.06 \pm 0.04$ \\
\hline 9 & 508.58 & 205.71 & $56.63 \pm 0.33$ & $85.86 \pm 0.096$ & $98.14 \pm 0.06$ \\
\hline 10 & 254.29 & 205.71 & $49.71 \pm 0.8$ & $75.90 \pm 0.05$ & $97.91 \pm 0.03$ \\
\hline 11 & 254.29 & 137.14 & $34.20 \pm 0.9$ & $68.11 \pm 0.73$ & $97.78 \pm 0.01$ \\
\hline 12 & 254.29 & 274.28 & $50.16 \pm 0.6$ & $83.77 \pm 0.72$ & $97.01 \pm 0.03$ \\
\hline 13 & 381.43 & 205.71 & $52.58 \pm 0.13$ & $88.11 \pm 0.77$ & $98.90 \pm 0.06$ \\
\hline Ketoprofen & & & $14.94 \pm 0.3$ & $22.79 \pm 0.56$ & \\
\hline
\end{tabular}

All values are expressed as mean $\pm S . D ., n=3$.

263 The responses, solubility $\left(\mathrm{Y}_{1}\right)$ and in-vitro drug release $\left(\mathrm{Y}_{2}\right)$ were fitted best into the quadratic response surface model with none transformation of the data. In different batches of KP-PABA co-crystal solubility values range from $34.20-60.11 \mu \mathrm{g} / \mathrm{ml}$ and $\%$ in-vitro drug release range for 68.11 to $93.45 \%$. This upheave in solubility and thus dissolution may be due to formation of soluble complex between ketoprofen and PABA. The solubility of KP-PABA co-crystal (60.11 $\mu \mathrm{g} / \mathrm{ml})$ was higher than that of the ketoprofen $(14.94 \mu \mathrm{g} / \mathrm{ml})$. The reason for this furtherance in solubility is the intermolecular hydrogen bonding between the ketoprofen and PABA and it is 270 surmised that this linkage may result in hydration of co-crystal and thereby, high solubility of the 271 drug is observed from co-crystal. 


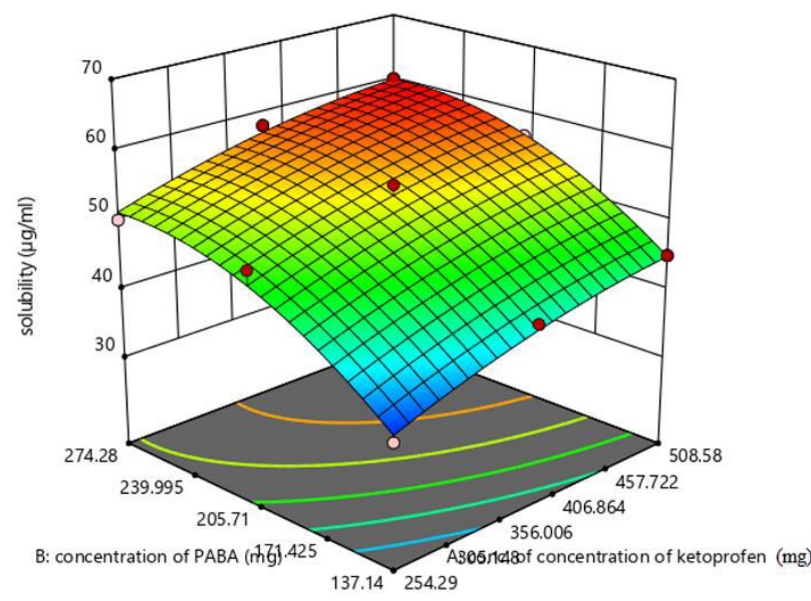

(a)

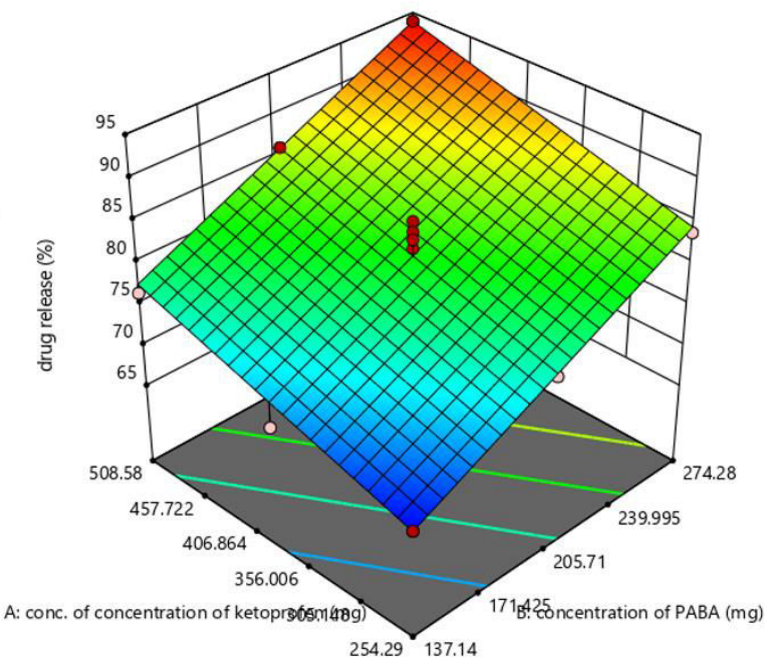

(b)
272

273

274

275

276

277

278

279

280

281

282

283

284

285

286

287

288

289

290

291

Figure 1. (a, b) Response surface plots displaying effect of concentration of ketoprofen (KP) \& PABA on solubility $\left(\mathrm{Y}_{1}\right)$ and in-vitro drug release $\left(\mathrm{Y}_{2}\right)$.

The polynomial models for the responses solubility $\left(\mathrm{Y}_{1}\right)$ and in-vitro drug release $\left(\mathrm{Y}_{2}\right)$ can also be expressed by the equation (6) and (7), respectively. The synergistic and antagonist effect is explained by the positive and negative coefficient value for specific independent variables in the polynomial equation (6) and (7), respectively. The equations generated revealed that both factors independently exerted a significant effect on the solubility and in-vitro drug release. The response surface plot [Figure $1(\mathrm{a}, \mathrm{b})$ ] revealed that solubility and in-vitro drug release vary in curvilinear fashion with an increase in the amount of each factor. However, the effect of the concentration of PABA $\left(\mathrm{X}_{2}\right)$ seems to be more pronounced as compared with that of concentration of ketoprofen $\left(\mathrm{X}_{1}\right)$.

$\mathrm{Y}_{1}=53.68+4.61 \mathrm{X}_{1}+7.81 \mathrm{X}_{2}-0.275 \mathrm{X}_{1} \mathrm{X}_{2}-1.45 \mathrm{X}_{1}^{2}-4.39 \mathrm{X}_{2}^{2}$

$\mathrm{Y}_{2}=42.218+0.037 \mathrm{X}_{1}+0.119 \mathrm{X}_{2}-0.317 \mathrm{X}_{1} \mathrm{X}_{2}-3.51 \mathrm{X}_{1}^{2}-3.31 \mathrm{X}_{2}^{2}$

The denouement of ANOVA test on the response surface quadratic model are summarized in Table II demonstrated that model was found significant with lack of fit as non-significant. A good correlation among experimental and predicted responses was specified with a good value of $\mathrm{R}^{2}$ (>0.9). The adequate precision measuring signal to noise ratio (greater than 4 ) is desirable. In this design, the ratio of 25.49 (solubility) and 23.05 (drug release) illustrated an adequate signal that let the model to navigate design space. Figure 1 (a\&b) display the combined effect of 
concentration of ketoprofen \& PABA on solubility and drug release. It can be interpreted from the plots that independent and dependent variables exists in a curvilinear correspondence. It is also inferred from the plot that higher level of ketoprofen \& PABA results in increase in solubility of formulation.

Table II. Model summary statistics

\begin{tabular}{|l|l|l|l|l|l|l|l|}
\hline \multicolumn{9}{|c|}{ Model } & \multicolumn{2}{l|}{ Lack of Fit } \\
\hline $\begin{array}{l}\text { Response } \\
\text { factors } \\
(Y)\end{array}$ & $\begin{array}{l}\text { F- } \\
\text { value }\end{array}$ & Prob.>F & $\mathbf{R}^{2}$ & $\begin{array}{l}\text { Adequate } \\
\text { Precision }\end{array}$ & $\begin{array}{l}\text { C.V } \\
(\%)\end{array}$ & $\begin{array}{l}\text { F- } \\
\text { value }\end{array}$ & Prob.>F \\
\hline$Y_{1}$ & 20.58 & $<0.0001$ & 0.975 & 25.49 & 2.81 & 2.31 & 0.218 \\
\hline$Y_{2}$ & 49.19 & $<0.0001$ & 0.907 & 23.05 & 2.88 & 1.56 & 0.34 \\
\hline
\end{tabular}

\section{Optimization}

The optimization equation 6 and 7, relating the response and independent factors, was fabricated based on a quadratic model. To the responses i.e. solubility and in-vitro drug release the desirability function was applied with constraints to obtain the higher magnitude of both. In this manner the formulation, containing PABA $(274.28 \mathrm{mg})$ as coformer and drug $(508.58 \mathrm{mg})$ with addition of acetic acid $(2 \%)$ solution at $60^{\circ} \mathrm{C}$, established the maximum desirability, was organized and evaluated.

The optimization of independent variables was done with constraints of maximum solubility and maximum $\%$ release. The different set of solutions are provided by the optimization tool in design expert software. The parameters suggested by the design were concentration of ketoprofen $(508.58 \mathrm{mg})$ \& concentration of PABA $(274.28 \mathrm{mg})$ that provide co-crystal with solubility of $60 \mu \mathrm{g} / \mathrm{ml}$ (predicted value $60.051 \mu \mathrm{g} / \mathrm{ml}$ ) and \% release $93.45 \%$ (predicted value 93.94\%). The closer concordance between observed and predicted values discerned high predictive ability of the model. Figure 2 displays the in vitro release profile of ketoprofen as pure drug and the optimized batch of formulation. 


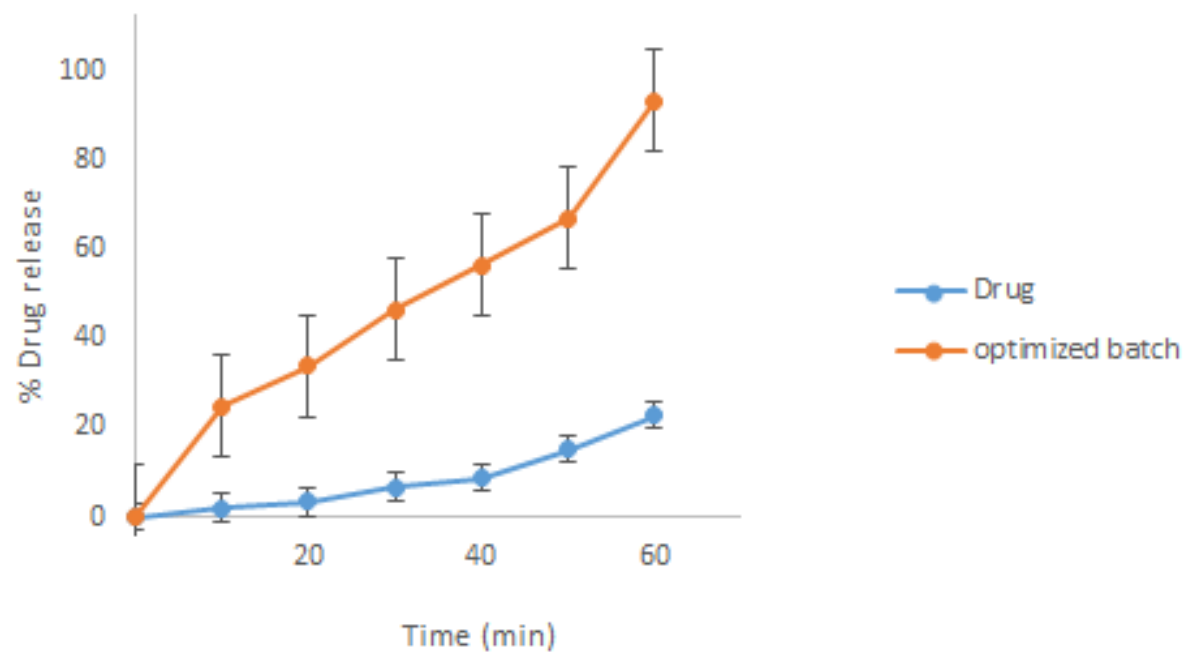

315 Figure 2. In-vitro release profile of pure drug (Ketoprofen) and KP-PABA co-crystal (optimized 316 batch).

317 The release profile of co-crystal is compared with equivalent concentration of pure drug solution 318 to study release rate kinetics. The release of ketoprofen from co-crystal formulation and drug 319 solution was put into various kinetic models to estimate the kinetics and mechanism of release 320 (Table III). The release rate data for the formulation was found to be fitted best into Zero order 321 model of release kinetics $\left(R^{2}=0.951\right)$. Further, the value of ' $n$ ' $>1.0(n=1.4)$ the release exponent 322 of Korsemeyer -Peppas equation indicated that the release of ketoprofen from co-crystal occurs 323 by super-case- 2 transport i.e. the release occurred by relaxation or erosion of polymer after 324 swelling in biological fluid.

325 Table III. Modeling and release kinetics of ketoprofen from co-crystal.

\begin{tabular}{lllllr}
\hline Formulation & Zero order & First order & Higuchi & \multicolumn{2}{c}{ KorsmeyerPeppas } \\
& $\mathrm{R}^{2}$ & $\mathrm{R}^{2}$ & $\mathrm{R}^{2}$ & $\mathrm{R}^{2}$ & $\mathrm{n}$ \\
\hline KP solution & 0.915 & 0.850 & 0.949 & 0.808 & 1.48 \\
\hline Co-crystal & 0.921 & 0.813 & 0.932 & 0.913 & 1.52 \\
\hline
\end{tabular}

328 FTIR is an analytical method used to study the changes in the position caused by the vibration modes of the functional groups. The FTIR spectra revealed the shift in characteristic peaks of 
330 drug and coformer due to co-crystal formation involving $\mathrm{H}$ bonding between the corresponding 331 functional groups. The spectra of ketoprofen figure 3 (a) showed characteristic absorption band at $2979.27 \mathrm{~cm}^{-1}$ due to $-\mathrm{CH}$ stretching. The peak appearing at $1697.76 \mathrm{~cm}^{-1}$ can be ascribed to $333 \mathrm{C}=\mathrm{O}$ stretching of acid while peak appearing at $1655.77 \mathrm{~cm}^{-1}$ is due to $-\mathrm{C}=\mathrm{O}$ stretching of 334 ketone. The absorption bands at $1598.67 \mathrm{~cm}^{-1} \quad(-\mathrm{C}=\mathrm{C}=$ stretching $), 1442.21 \mathrm{~cm}^{-1} \quad(-\mathrm{C}=\mathrm{O}$ 335 stretching of aromatic ring), $1420.59 \mathrm{~cm}^{-1}$ (-C-H deformation of $\mathrm{CH}_{3}$ asymmetrical) and 1370.04 $336 \mathrm{~cm}^{-1}$ (-C-H deformation of $\mathrm{CH}_{3}$ symmetrical) also appeared. The spectra of PABA presented the 337 characteristic absorption band of $-\mathrm{NH}$ stretch appearing at $3461.24 \mathrm{~cm}^{-1}$, peak at $3362.37 \mathrm{~cm}^{-1}$ is 338 due to $-\mathrm{OH}$ stretch, peak at 1681.89 is attributed to $-\mathrm{C}=\mathrm{C}$ aromatic stretching while peak at $3391422 \mathrm{~cm}^{-1}$ may be ascribed to $-\mathrm{C}-\mathrm{C}$ aromatic stretching. In FTIR spectra of KP-PABA co-crystal 340 the peak due to $-\mathrm{C}=\mathrm{O}$ stretching of $-\mathrm{COOH}$ group of ketoprofen shifted from $1697.76 \mathrm{~cm}^{-1}$ to $3411664.16 \mathrm{~cm}^{-1}$. There was shift in $-\mathrm{NH}$ stretch from $3362.37 \mathrm{~cm}^{-1}$ (PABA) to $3360.95 \mathrm{~cm}^{-1}$ (KP342 PABA co-crystal). These observations suggested formation of hydrogen bond between amino 343 group of PABA and - $\mathrm{COOH}$ group of ketoprofen in KP-PABA co-crystal.

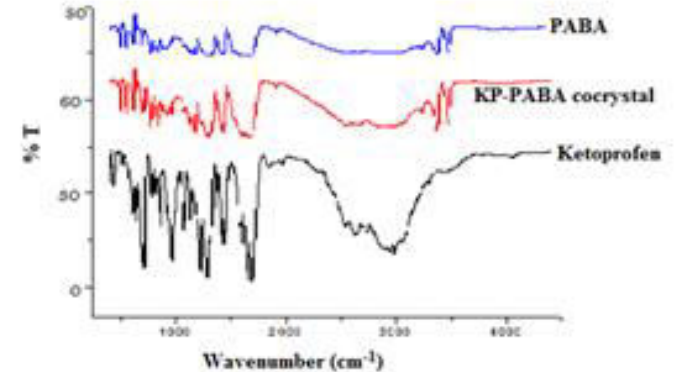

(a)

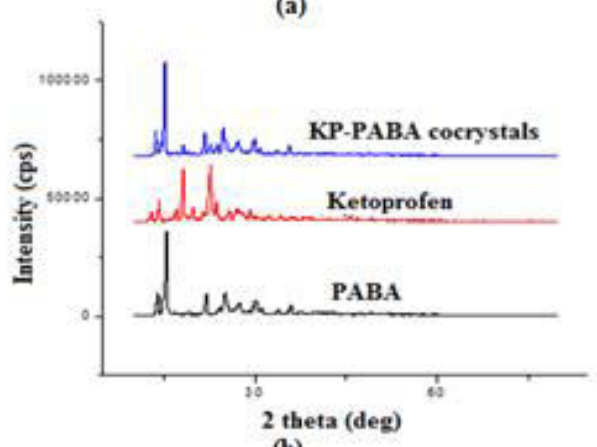

(b)

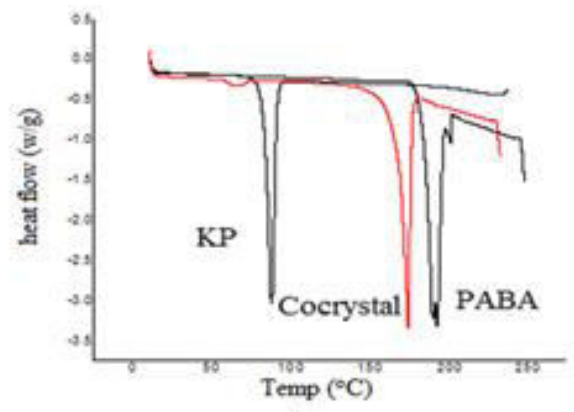

(c)

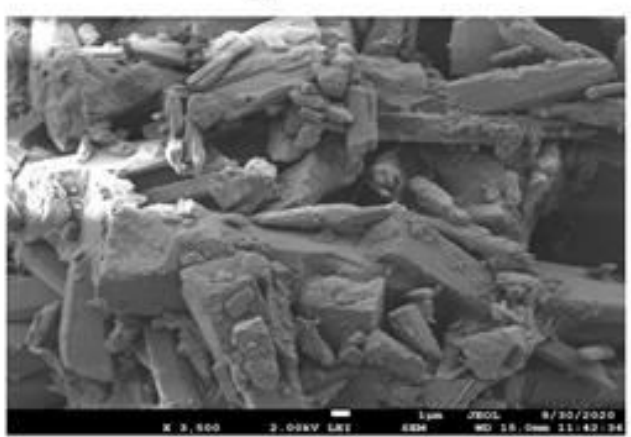

(d)

345 Figure 3. (a) FTIR, (b) XRD, (c) DSC spectra of ketoprofen, PABA and optimized batch of KPPABA co-crystal, (d) SEM image of optimized batch of KP-PABA co-crystal. 


\section{Powder X-ray diffraction (PXRD)}

349

The X-ray diffraction spectra of ketoprofen, PABA and optimized batch of KP-PABA co-crystal is illustrated in figure 3 (b). In diffraction spectra of ketoprofen the peaks (and Miller indices) appeared at $2 \theta$ of 12.74 (100), 18.52 (200), 22.85 (211), 24.00 (221), 26.32 (222), 28.920 (300) whereas, in XRD spectra of PABA the peaks (and Miller indices) appeared 15.33(121), 22.67 (211), 24.88 (221), 27.18 (222) and 30.65 (310) that manifested crystalline structure of ketoprofen and PABA respectively. The major diffraction peaks at 29, 13.32 (100), 15.90 (121), 18.8 (200), 21.69 (210), 25.45 (221) and 27.19 (222) were also observed is PXRD spectra of cocrystal that portrayed crystalline nature of formulation this indicating that resultant product is also crystalline in nature [43]. Moreover, some characteristic peaks of ketoprofen at 12.74, 22.85, and 28.92 disappeared while some peaks at 24.00 and 26.32 shifted to 25.45 and 27.19, respectively. Besides this, few peaks of PABA at 22.67 and 30.65 disappeared and few peaks at $15.33,24.88$, and 27.18 shifted to $15.90,25.45$, and 27.19 , respectively. These changes in the PXRD data of respective co-crystal from ketoprofen and coformer are suggestive of the formation of new forms.

\section{Differential scanning calorimetry (DSC)}

DSC thermogram (Figure 3 (c)) of ketoprofen displayed a sharp single peak at $94.5^{\circ} \mathrm{C}$ that corresponds to its melting point. The peak at $187.8^{\circ} \mathrm{C}$ attributed to melting point of PABA. However, in the DSC curve of co-crystal a single endothermic peak appearing at $180^{\circ} \mathrm{C}$ suggested the presence of a new phase (co-crystal) different from the constitutional components. The modification in the melting point is due to the alteration in the crystal lattice of the drug in the presence of coformer, indicating that certain modification has occurred.

\section{Scanning electron microscopy (SEM)}

The SEM image of the co-crystal formulation was depicted in figure 3 (d). The co-crystal showed good crystalline characteristics. This crystalline characteristic of co-crystal was reinforced by the XRD data, as discussed earlier. The pores over the surface of the co-crystal may brace the imbibition of the solvent/biological fluids, consequently, increasing the solubility and bioavaibility of ketoprofen as anticpated. 
378 Nuclear magnetic resonance spectroscopy is used to characterize the co-crystal by studying the 379 chemical environment of their nuclei and hydrogen bonding and it also offers valuable 380 information regarding interactions. In the NMR spectra of KP-PABA co-crystal, the carbonyl 381 carbon of ketoprofen corresponding to $196.46 \mathrm{ppm}$ and140.13 ppm has shifted to $196.12 \mathrm{ppm}$ 382 and $142.23 \mathrm{ppm}$, respectively. A deviation in the carbonyl carbon of carboxylic group in PABA 383 shifted from $173.84 \mathrm{ppm}$ and $152.13 \mathrm{ppm}$ to $175.52 \mathrm{ppm}$ and $153.60 \mathrm{ppm}$, respectively (Figure 384 4). This suggests an interaction between amino group of PABA and-COOH group of ketoprofen 385 in KP-PABA co-crystal.

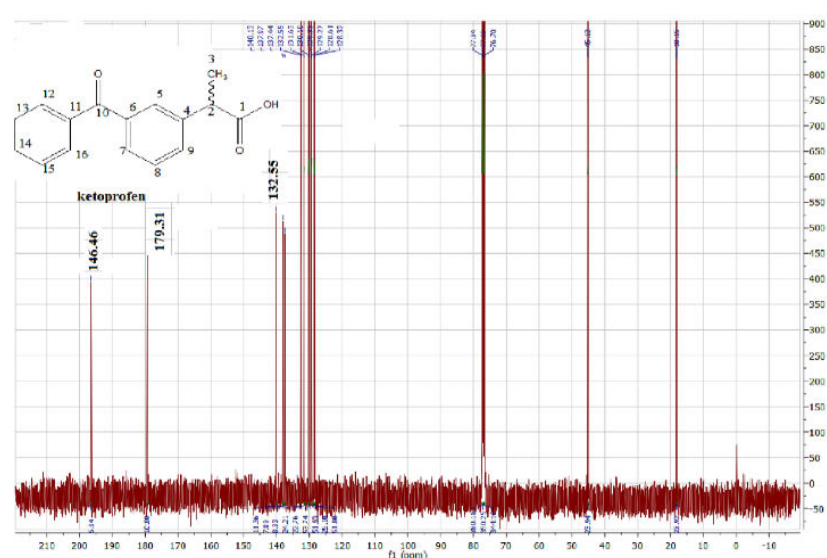

(a)

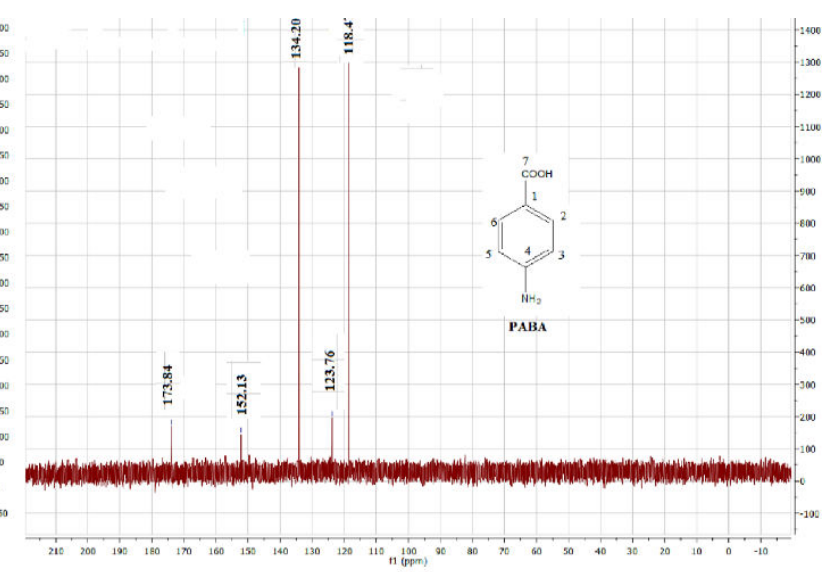

(b)

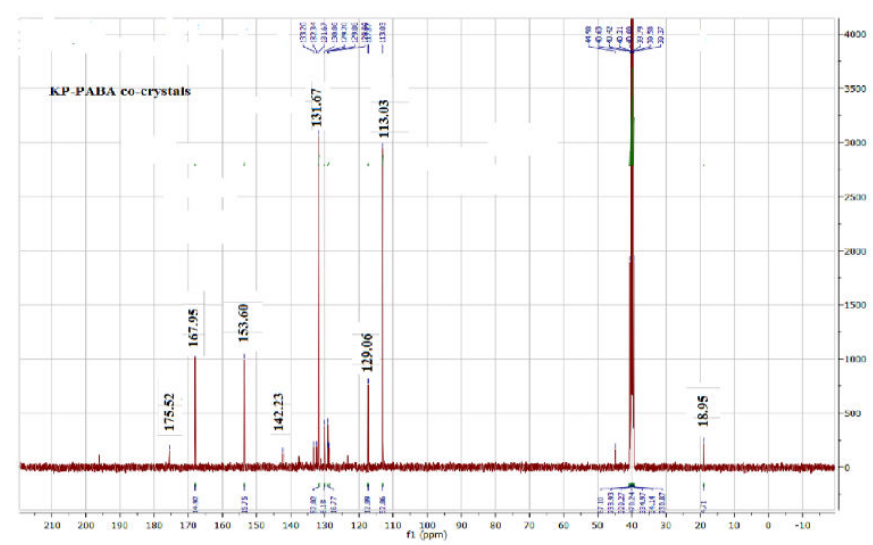

(c)

Figure 4. NMR spectroscopy of (a) ketoprofen, (b) PABA and (c) KP-PABA co-crystal. 


\section{Non-covalent interactions (NCI) analysis}

391

Co-crystal involve no covalent modification of its constituents and different chemical 392 constituents interact through non covalent interactions [44]. In order to identify the type of 393 interactions that may be present in the cocrystal of ketoprofen and PABA, the NCI analysis was carried out. The chemical structures of ketoprofen and PABA were retrieved from pubchem database [https://pubchem.ncbi.nlm.nih.gov]. The two structures were combined and the system was minimized with molecular mechanics force field. This minimized system was further minimized using new and more accurate PM7 method by taking value of $\mathrm{g}_{\text {norm }}$ as 0.001 in MOPAC [45]. Different properties of the final minimized cocrystal were calculated by DFT using 6-31G* basis set in B3LYP method of Firefly [46]. The interactions were determined using Multiwfn [47] and VMD [48].

Reduced density gradient (RDG) calculations show that one hydrogen bond is formed between carbonyl oxygen of the ketoprofen and hydrogen atom of amino group of PABA. Aromatic rings of both the molecules stacked against each other through pi-pi stacking interactions. Carbonyl oxygen atom of PABA made weak interactions with hydrogen atoms of terminal phenyl ring of ketoprofen. These interactions are shown in figure 5 (a) below:

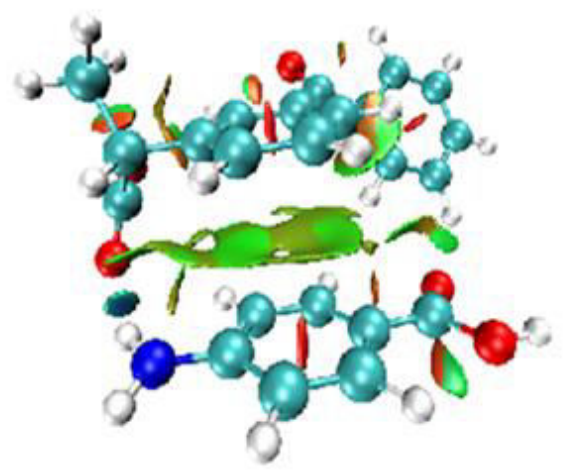

(a)

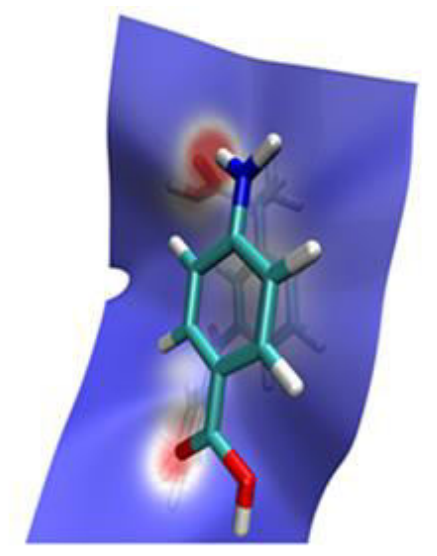

(b)

Figure 5. (a) RDG iosurface of ketoprofen-PABA cocrystal. Blue color indicates hydrogen bond and green and brown colors indicate weak Van der Waals interactions, (b) Hirshfeld surface mapped by electron density with promolecular approximation of ketopofen-PABA co-crystal. 
411 Further, Hirshfeld surface mapped by electron density with promolecular approximation analysis 412 was also performed to study the hydrogen bond and Van der waals interactions. Figure 5 (b) 413 shown here clearly indicate the region of high electron density in red color between PABA 414 amino and ketoprofen carbonyl groups. Another one is present between PABA carbonyl and 415 terminal phenyl protons of ketoprofen whereas white region between two aromatic rings depicts 416 lesser electron density means weaker interactions blue color indicates electron free region.

\section{Biological evaluation of KP-PABA co-crystal}

\section{In-vitro anti-inflammatory activity}

419 The compared plot of \% inhibition of protein denaturation at different concentration of optimized 420 formulation and pure drug is shown in figure 6 (a). The plot displayed that as the concentration 421 of drug is increased, the \% inhibition is also got increased whereas the effect is more prominent 422 at lower concentration range of drug. Nonlinear regression analysis was used to calculate the half 423 maximal inhibitory concentration $\left(\mathrm{IC}_{50}\right)$ values of ketoprofen and optimized formulation. The $424 \mathrm{IC}_{50}$ values were $34.04 \mu \mathrm{M}$ for ketoprofen and $4.373 \mu \mathrm{M}$ for optimized formulation [Figure 6 425 (b)], there is almost 8 fold improvement in $\mathrm{IC}_{50}$ value. Hence, it is concluded that co-crystal 426 formulation is more active in producing anti-inflammatory response than the drug ketoprofen.

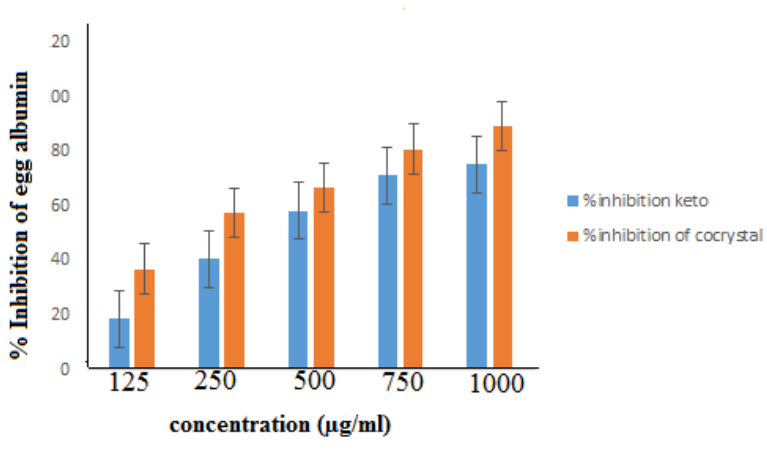

(a)

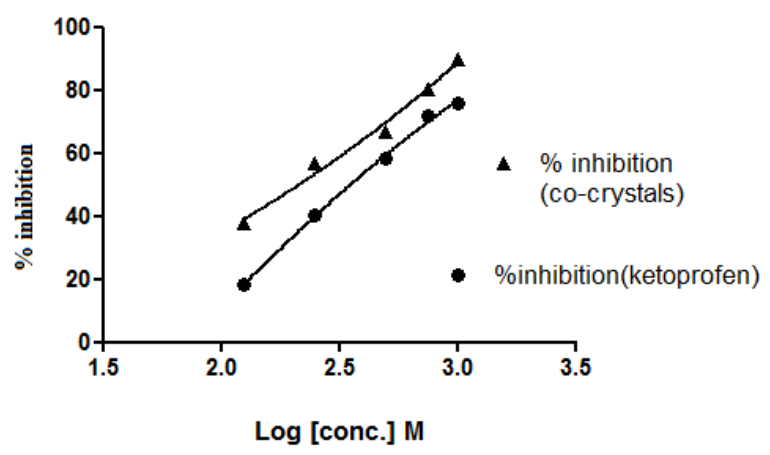

(b)

428 Figure 6. (a) Percent inhibition of ketoprofen and optimized formulation, (b) $\mathrm{IC}_{50}$ values 429 calculated using GraphPad Prism 5.0 for Windows.

\section{$430 \quad$ In-vivo anti-inflammatory activity}

431 Carrageenan induced rat paw edema method was appertained to compare oral efficacy of 432 ketoprofen and optimized batch of KP-PABA co-crystal formulation. The improvement in 
433 activity of ketoprofen and co-crystal formulation was comparatively assesed by the increase in 434 paw volume of control groups. The paw edema volume estimates (before and after drug 435 administration) and \% inhibition of edema at different time interval was persuaded and displayed 436 in Table IV. The co-crystal and ketoprofen unveiled inhibition of paw edema as $66.14 \pm 0.04 \%$ 437 and $58.16 \pm 0.03 \%$ at the end of $6 \mathrm{~h}$, respectively thus demonstrating quick onset of action by co438 crystal in contrast with the pure drug ketoprofen.

439 Statical Analysis:- Data was compared by ANOVA followed by Tukey's test. The p value is $440<0.0005$ is considered as significant.

441 Table IV. Effect of ketoprofen and ketoprofen-PABA formulation on the paw edema induced by 442 carrageenan in Wistar rats.

\begin{tabular}{|l|l|l|l|l|l|}
\hline \multirow{2}{*}{$\begin{array}{l}\text { Time } \\
(\mathbf{m i n})\end{array}$} & \multicolumn{2}{|l|}{ Paw volume } \\
\cline { 2 - 6 } & \multicolumn{2}{|l|}{$(\mathbf{m m})$} & $\begin{array}{l}\text { Inibition } \\
(\%)\end{array}$ \\
\cline { 2 - 6 } & Control & Pure drug & Co-crystal & Pure drug & Co-crystal \\
\hline 60 & $4.22 \pm 0.01$ & $4.06 \pm 0.02^{*}$ & $4.01 \pm 0.01^{*}$ & $3.73 \pm 0.03$ & $4.77 \pm 0.05^{\#}$ \\
\hline 120 & $4.55 \pm 0.12$ & $3.83 \pm 0.08^{*}$ & $3.71 \pm 0.14^{*}$ & $15.78 \pm 0.01$ & $18.48 \pm 0.04^{\#}$ \\
\hline 180 & $4.90 \pm 0.101$ & $3.44 \pm 0.04^{*}$ & $3.17 \pm 0.07^{*}$ & $30.61 \pm 0.03$ & $35.45 \pm 0.22^{\#}$ \\
\hline 240 & $5.37 \pm 0.189$ & $3.21 \pm 0.03^{*}$ & $3.02 \pm 0.03^{*}$ & $40.29 \pm 0.10$ & $43.78 \pm 0.04^{\#}$ \\
\hline 300 & $6.02 \pm 0.16$ & $3.048 \pm 0.042^{*}$ & $2.863 \pm 0.61^{*}$ & $49.31 \pm 0.18$ & $59.64 \pm 0.17^{\#}$ \\
\hline 360 & $6.44 \pm 0.03$ & $2.671 \pm 0.01^{*}$ & $2.138 \pm 0.03^{*}$ & $58.16 \pm 0.03$ & $66.14 \pm 0.04^{\#}$ \\
\hline
\end{tabular}

443 All values are expressed as mean \pm S.D., $n=6 ;{ }^{*}$ Significant $(p<0.05)$ compared to control; ${ }^{\#}$ Significant $(p<0.05)$ compared 444 to pure drug (ketoprofen).

\section{$445 \quad$ Analgesic activity}

446 The results of the \% analgesic activity (PAA) of test, reference and control group are shown in 447 Table 5. The PAA (equation 5) was comparatively evaluated for KP-PABA co-crystal and pure 448 drug based on its potential to suppress pain. KP-PABA co-crystal showed significant effect in 449 enhancing the pain thershold to a certain extent when compared to that of drug (ketoprofen), 450 thus, stipulating that an improvement in solubility further tweaked the pharmacological response. 
Table 5. \% Analgesic effect of ketoprofen and KP-PABA by tail flick method in mice.

\begin{tabular}{lllllll}
\hline Treatment & \multicolumn{5}{c}{ PAA } \\
\cline { 2 - 6 } & $\mathbf{0 h}$ & $\mathbf{1 h}$ & $\mathbf{2 h}$ & $\mathbf{3 h}$ & $\mathbf{4 h}$ & $\mathbf{5 h}$ \\
\hline $\begin{array}{l}\text { Standard } \\
\text { (ketoprofen) }\end{array}$ & $0.03 \pm 0.020$ & $31.30 \pm 0.71^{*}$ & $35.18 \pm 0.12^{*}$ & $42.36 \pm 0.17^{*}$ & $50.93 \pm 0.14^{*}$ & $71.96 \pm 0.17$ \\
$\begin{array}{l}\text { Test } \\
\text { KP-PABA }\end{array}$ & $0.02 \pm 0.011$ & $35.51 \pm 0.15^{*}$ & $48.63 \pm 0.61^{*}$ & $55.84 \pm 0.14^{\#}$ & $67.82 \pm 0.16^{\#}$ & $78.92 \pm 0.32$ \\
$\begin{array}{l}\text { co-crystal } \\
\text { Control }\end{array}$ & $0.01 \pm 0.012$ & $0.91 \pm 0.19$ & $1.32 \pm 0.02$ & $0.83 \pm 0.10$ & & \\
(vehicle) & & & & & & \\
\end{tabular}

$453 \quad$ All values are expressed as mean \pm S.D., $n=6 .{ }^{*}$ Significant $(p<0.05)$ compared to control. ${ }^{\sharp S i g n i f i c a n t ~}(p<0.05)$ compared to 454 pure drug (ketoprofen).

\section{CONCLUSION}

456 Ketoprofen-p-aminobenzoic acid co-crystals were prepared by solvent evaporation technique 457 employing central composite experimental design. The optimized batch containing ketoprofen 458 and PABA in molar ratio (1:1) after characterization by FT-IR, XRD, DSC, SEM and NMR 459 studies was further evaluated for in-vitro and in-vivo anti-inflammatory and analgesic activities. 460 The solubility and \% drug release of different batches of co-crystal was found to be between $46134.20-60.11 \mu \mathrm{g} / \mathrm{ml}$ and $68.11-93.45 \%$, respectively. The results of in-vivo anti-inflammatory 462 activity by rat paw edema method provided a significant \% inhibition in paw volume by co463 crystal formulation as compared to standard drug in wistar rats whereas in-vivo analgesic activity 464 further showed that pain thershold has significantly enhanced. The half maximal inhibitory 465 concentration $\left(\mathrm{IC}_{50}\right)$ values for in-vitro anti-inflammatory activity exhibited almost 8-fold 466 amplification in activity indicating higher anti-inflammatory effect of optimized co-crystal batch 467 as compared to pure drug ketoprofen. On that account, it can be concluded that co-crystallization 468 proves to be a promissing technique for enhancing the solubility characteristics of BCS -II drugs.

\section{CONFLICT OF INTEREST}

470 The authors report no conflicts of interest.

\section{Statement of Animal Rights}


472 The procedure followed for animal handling is in accordance with the protocol as approved for 473 animal study (CPCSEA Reg. no-IAEC/2020/10-18) by the Institutional Animal Ethical 474 Committee, Guru Jambheshwar University of Science and Technology, Hisar, India.

475

476 


\section{REFERENCES}

478

479

480

481

482

483

484

485

486

487

488

489

490

491

492

493

494

495

496

497

498

499

500

501

502

503

504

505

506

507

1. Sarraguça, M. C., Ribeiro, P. R., Dos Santos, A. O., \& Lopes, J. A. (2015). Batch statistical process monitoring approach to a cocrystallization process. Journal of pharmaceutical sciences, 104(12), 4099-4108, https://doi.org/10.1002/jps.24623.

2. Soares, F. L., \& Carneiro, R. L. (2013). Green synthesis of ibuprofen-nicotinamide cocrystals and in-line evaluation by Raman spectroscopy. Crystal growth \& design, 13(4), 1510-1517., https://doi.org/10.1021/cg3017112.

3. Harriss, B. I., Vella-Zarb, L., Wilson, C., \& Evans, I. R. (2014). Furosemide cocrystals: Structures, hydrogen bonding, and implications for properties. Crystal growth \& design, 14(2), 783-791, https://doi.org/10.1021/cg401662d.

4. Padrela, L., Rodrigues, M. A., Velaga, S. P., Matos, H. A., \& de Azevedo, E. G. (2009). Formation of indomethacin-saccharin cocrystals using supercritical fluid technology. European Journal of Pharmaceutical Sciences,38(1), 9-17, https://doi.org/10.1016/j.ejps.2009.05.010.

5. Chow, S. F., Shi, L., Ng, W. W., Leung, K. H. Y., Nagapudi, K., Sun, C. C., \& Chow, A. H. (2014). Kinetic entrapment of a hidden curcumin cocrystal with

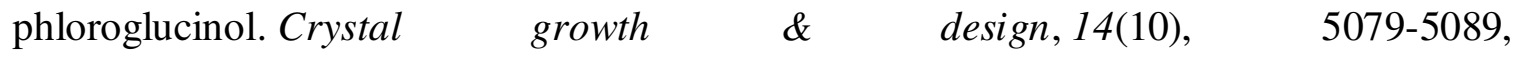
https://doi.org/10.1021/cg5007007.

6. Childs, S. L., Stahly, G. P., \& Park, A. (2007). The salt- cocrystal continuum: the influence of crystal structure on ionization state. Molecular pharmaceutics, 4(3), 323338 , https://doi.org/10.1021/mp0601345.

7. Berry, D. J., \& Steed, J. W. (2017). Pharmaceutical cocrystals, salts and multicomponent systems; intermolecular interactions and property based design. Advanced drug delivery reviews, 117, 3-24, https://doi.org/10.1016/j.addr.2017.03.003.

8. da Silva, C. C., Pepino, R. D. O., de Melo, C. C., Tenorio, J. C., \& Ellena, J. (2014). Controlled Synthesis of New 5-Fluorocytosine Cocrystals Based on the $\mathrm{p} \mathrm{K}$ a Rule. Crystal Growth \& Design, 14(9), 4383-4393, https://doi.org/10.1021/cg500502j.

9. Aitipamula, S., Chow, P. S., \& Tan, R. B. (2014). Polymorphism in cocrystals: a review and assessment of its significance. CrystEngComm, 16(17), 3451-3465, https://doi.org/10.1039/C3CE42008F. 
10. Lee, K. S., Kim, K. J., \& Ulrich, J. (2015). Formation of Salicylic Acid/4, 4'-Dipyridyl Cocrystals Based on the Ternary Phase Diagram. Chemical Engineering \& Technology, 38(6), 1073-1080, https://doi.org/10.1002/ceat.201400738

11. Shayanfar, A., \& Jouyban, A. (2014). Physicochemical characterization of a new cocrystal of ketoconazole. Powder technology, 262,

242-248, https://doi.org/10.1016/j.powtec.2014.04.072.

12. Ganesh, M., Ubaidulla, U., Rathnam, G., \& Jang, H. T. (2019). Chitosan-telmisartan 515 polymeric cocrystals for improving oral absorption: In vitro and in vivo evaluation. International journal of biological macromolecules, 131, 879-885, https://doi.org/10.1016/j.ijbiomac.2019.03.141.

13. Mutalik, S., Anju, P., Manoj, K., \& Usha, A. N. (2008). Enhancement of dissolution rate and bioavailability of aceclofenac: a chitosan-based solvent change approach. International journal of pharmaceutics,350(1-2), 279-290, https://doi.org/10.1016/j.ijpharm.2007.09.006.

14. Alvani, A., Jouyban, A., \& Shayanfar, A. (2019). The effect of surfactant and polymer on solution stability and solubility of tadalafil-methylparaben cocrystal. Journal of Molecular Liquids, 281, 86-92, https://doi.org/10.1016/j.molliq.2019.02.080.

15. Rahman, Z., Agarabi, C., Zidan, A. S., Khan, S. R., \& Khan, M. A. (2011). Physicomechanical and stability evaluation of carbamazepine cocrystal with nicotinamide. Aaps Pharmscitech, 12(2), 693-704, https://doi.org/10.1208/s12249-011-9603-4.

16. Lyn, L. Y., Sze, H. W., Rajendran, A., Adinarayana, G., Dua, K., \& Garg, S. (2011). Crystal modifications and dissolution rate of piroxicam. Acta Pharmaceutica, 61(4), 391402, https://doi.org/10.2478/v10007-011-0037-z.

17. Zhang, Y. X., Wang, L. Y., Dai, J. K., Liu, F., Li, Y. T., Wu, Z. Y., \& Yan, C. W. (2019). The comparative study of cocrystal/salt in simultaneously improving solubility and permeability of acetazolamide. Journal of Molecular Structure, 1184, 225-232, https://doi.org/10.1016/j.molstruc.2019.01.090.

18. Gautam, M. K., Besan, M., Pandit, D., Mandal, S., \& Chadha, R. (2019). Cocrystal of 5fluorouracil: Characterization and evaluation of biopharmaceutical parameters. AAPS PharmSciTech, 20(4), 149, https://doi.org/10.1208/s12249-019-1360-9. 
19. Kaleemullah M., Jiyauddin K., Thiban E., Raska S., AL-dhalli S., Budiasih S., Gamal O.E., Fadli A., \& Eddyi Y. Development and evaluation of ketoprofen sustained release matrix tablet using Hibiscus rosa- sinensis leaves mucilage. Saudi pharmaceutical Journal 25(5): 770-779, https://doi.org/10.1016/j.jsps.2016.10.006.

20. Bhatia, M., \& Devi, S. Development, Characterisation and Evaluation of PVP K-30/PEG Solid Dispersion Containing Ketoprofen. ACTA Pharmaceutica Sciencia,58(1), DOI: 10.23893/1307-2080.APS.05806.

21. Bhatia, M., \& Devi, R. (2019). Enhanced Solubility and Drug Release of Ketoprofen Using Lyophilized Bovine Serum Albumin Solid Dispersion. ACTA Pharmaceutica Sciencia, 57(1), DOI: 10.23893/1307-2080.APS.05703.

22. Vittal, G. V., Deveswaran, R., Bharath, S., Basavaraj, B. V., \& Madhavan, V. (2012). Formulation and characterization of ketoprofen liquisolid compacts by Box-Behnken design. International journal of pharmaceutical investigation,2(3), 150, doi: $\underline{10.4103 / 2230-973 X .104398}$.

23. Nikumbh, K. V., Sevankar, S. G., \& Patil, M. P. (2015). Formulation development, in vitro and in vivo evaluation of microemulsion-based gel loaded with ketoprofen. Drug delivery, 22(4), 509-515, https://doi.org/10.3109/10717544.2013.859186.

24. Ambala, R., \& Vemula, S. K. (2015). Formulation and characterization of ketoprofen emulgels. Journal of Applied Pharmaceutical Science,5(7), 112-117, DOI: 10.7324/JAPS.2015.50717.

25. Attia, M. F., Anton, N., Khan, I. U., Serra, C. A., Messaddeq, N., Jakhmola, A.,\& Vandamme, T. (2016). One-step synthesis of iron oxide polypyrrole nanoparticles encapsulating ketoprofen as model of hydrophobic drug. International Journal of Pharmaceutics, 508(1-2), 61-70, https://doi.org/10.1016/j.ijpharm.2016.04.073.

26. Shah, P. P., Desai, P. R., \& Singh, M. (2012). Effect of oleic acid modified polymeric bilayered nanoparticles on percutaneous delivery of spantide II and ketoprofen. Journal of controlled release, 158(2), 336-345, https://doi.org/10.1016/j.jconrel.2011.11.016.

27. Gul, R., Ahmed, N., Ullah, N., Khan, M. I., \& Elaissari, A. (2018). Biodegradable ingredient-based emulgel loaded with ketoprofen nanoparticles. AAPS PharmSciTech, 19(4), 1869-1881, https://doi.org/10.1208/s12249-018-0997-0. 
28. Kheradmandnia, S., Vasheghani-Farahani, E., Nosrati, M., \& Atyabi, F. (2010). Preparation and characterization of ketoprofen-loaded solid lipid nanoparticles made from beeswax and carnauba wax. Nanomedicine: Nanotechnology, Biology and Medicine, 6(6), 753-759, https://doi.org/10.1016/j.nano.2010.06.003.

29. Xi, M. M., Wang, X. Y., Fang, K. Q., \& Gu, Y. (2005). Study on the characteristics of pectin-ketoprofen for colon targeting in rats. International journal of pharmaceutics, 298(1), 91-97, https://doi.org/10.1016/j.ijpharm.2005.04.012.

30. Kluge, J., Fusaro, F., Mazzotti, M., \& Muhrer, G. (2009). Production of PLGA microand nanocomposites by supercritical fluid extraction of emulsions: II. Encapsulation of Ketoprofen. The Journal of Supercritical Fluids, 50(3), 336-343, https://doi.org/10.1016/j.supflu.2009.05.002.

31. Perpétuo, G. L., Chierice, G. O., Ferreira, L. T., Fraga-Silva, T. F. C., Venturini, J., Arruda, M. S. P.,\& Castro, R. A. E. (2017). A combined approach using differential scanning calorimetry with polarized light thermomicroscopy in the investigation of ketoprofen and nicotinamide cocrystal. Thermochimica Acta, 651, 1-10, https://doi.org/10.1016/j.tca.2017.02.014.

32. Sanphui, P., Kumar, S. S., \& Nangia, A. (2012). Pharmaceutical cocrystals of niclosamide. Crystal growth \& design, 12(9), 4588-4599, https://doi.org/10.1021/cg300784v.

33. Bhogala, B. R., Basavoju, S., \& Nangia, A. (2005). Tape and layer structures in cocrystals of some di-and tricarboxylic acids with 4, 4'-bipyridines and isonicotinamide. From binary to ternary cocrystals. Cryst Eng Comm,7(90), 551-562, https://doi.org/10.1039/B509162D.

34. Sarkar, A., \& Rohani, S. (2015). Cocrystals of acyclovir with promising physicochemical properties. Journal of pharmaceutical sciences, 104(1), 98-105, https://doi.org/10.1002/jps.24248

35. Farrag, Y., Ide, W., Montero, B., Rico, M., Rodríguez-Llamazares, S., Barral, L., \& Bouza, R. (2018). Preparation of starch nanoparticles loaded with quercetin using nanoprecipitation technique. International journal of biological macromolecules, 114, 426-433, https://doi.org/10.1016/j.ijbiomac.2018.03.134. 
36. Luo, Y., Chen, S., Zhou, J., Chen, J., Tian, L., Gao, W.,\& Zhou, Z. (2019). Luteolin cocrystals: Characterization, evaluation of solubility, oral bioavailability and theoretical calculation. Journal of Drug Delivery Science and Technology,50, 248-254, https://doi.org/10.1016/j.jddst.2019.02.004.

37. Chavan, R. R., \& Hosamani, K. M. (2018). Microwave-assisted synthesis, computational studies and antibacterial/anti-inflammatory activities of compounds based on coumarinpyrazole hybrid. Royal

Society

open

science, 5(5),

172435, https://doi.org/10.1098/rsos.172435.

38. Alshaikh, R. A., Essa, E. A., \& El Maghraby, G. M. (2019). Eutexia for enhanced dissolution rate and anti-inflammatory activity of nonsteroidal anti-inflammatory agents: Caffeine as a melting point modulator. International journal of pharmaceutics, 563, 395405, https://doi.org/10.1016/j.ijpharm.2019.04.024.

39. Komakech, R., Kim, Y. G., Matsabisa, G. M., \& Kang, Y. (2019). Anti-inflammatory and analgesic potential of Tamarindus indica Linn.(Fabaceae): a narrative review. Integrative Medicine Research, 8(3), 181-186, https://doi.org/10.1016/j.imr.2019.07.002

40. Mondal, A., Maity, T. K., \& Bishayee, A. (2019). Analgesic and Anti-Inflammatory Activities of Quercetin-3-methoxy-4'-glucosyl-7-glucoside Isolated from Indian Medicinal Plant Melothria heterophylla. Medicines, 6(2), 59,

\section{https://doi.org/10.3390/medicines6020059.}

41. Khullar, R., Kumar, D., Seth, N., \& Saini, S. (2012). Formulation and evaluation of mefenamic acid emulgel for topical delivery. Saudi pharmaceutical journal, 20(1), 63-67, https://doi.org/10.1016/j.jsps.2011.08.001.

42. Kulkarni, S. K. (1980). Heat and other physiological stress-induced analgesia: catecholamine mediated and naloxone reversible response. Life sciences, 27(3), 185-188, https://doi.org/10.1016/0024-3205(80)90136-8.

43. Sun, S., Zhang, X., Cui, J., \& Liang, S. (2020). Identification of the Miller indices of a crystallographic plane: a tutorial and a comprehensive review on fundamental theory, universal methods based on different case studies and matters needing attention. Nanoscale, 12(32), 16657-16677, https://doi.org/10.1039/D0NR03637D.

44. Yadav, A. V., Shete, A. S., Dabke, A. P., Kulkarni, P. V., \& Sakhare, S. S. (2009). Cocrystal: a novel approach to modify physicochemical properties of active pharmaceutical 
629

630

631

632

633

634

635

636

637

638

639

640

641

642

643

644

645

646

647

648

38

40

43

ingredients. Indian journal of pharmaceutical sciences, 71(4), 359, 10.4103/0250$\underline{474 X .57283}$.

45. Stewart, J. J. P. (2016). Stewart Computational Chemistry, MOPAC2016. Colorado Springs. Available online at: http://OpenMOPAC. net.

46. Alex A. Granovsky, Firefly version 8, www,
http://classic.chem.msu.su/gran/firefly/index.html

47. Tian Lu, Feiwu Chen, J. Comput. Chem., 33, 580-592 (2012).

48. Humphrey, W., Dalke, A., \& Schulten, K. (1996). VMD-Visual Molecular Dynamics, J Molec Graphics.

639

41

42

44 